\title{
Fluoroquinolone Resistance in Clinical Isolates of Klebsiella Pneumoniae
}

\author{
Pacha Venkataramana Geetha ${ }^{1} \quad$ Kayanam Vijaya Lalitha Aishwarya ${ }^{1}$ Shanthi Mariappan ${ }^{1} \quad$ Uma Sekar $^{1}$ \\ ${ }^{1}$ Department of Microbiology, Sri Ramachandra Institute of Higher \\ Education and Research, Porur, Chennai, Tamil Nadu, India \\ Address for correspondence Geetha P.V., MSc, Department of \\ Microbiology, Sri Ramachandra Institute for Higher Education \\ and Research, Porur, Chennai 600116, Tamil Nadu, India \\ (e-mail: gethu16@gmail.com).
}

J Lab Physicians:2020;12:121-125

\begin{abstract}
Introduction Fluoroquinolones are widely used broad-spectrum antibiotics. Recently, increased rate of resistance to this antibiotic has been observed in Klebsiella pneumoniae. The aim of the present study was to determine the presence of quinolone resistance determining regions (QRDR) mutation genes and plasmid-mediated quinolone resistance (PMQR) determinants in clinical isolates of ciprofloxacin-resistant K. pneumoniae.

Material and Methods The study included 110 nonduplicate ciprofloxacin-resistant K. pneumoniae clinical isolates. Antibiotic susceptibility testing by disk diffusion method and minimum inhibitory concentration (MIC) by agar dilution methods for ciprofloxacin was performed according to the recommendations of Clinical Laboratory Standards Institute. The presence of QRDR genes and PMQR genes was screened by polymerase chain reaction (PCR) amplification.

Result All 110 isolates were resistance to ciprofloxacin, levofloxacin, and ofloxacin. As much as $88 \%$ of the isolates exhibited high-level of MIC to ciprofloxacin. Among the 110 isolates, $94(85 \%)$ harbored gyrA and $85(77 \%)$ gyrB. The parC and parE genes were detected in $88(80 \%)$ and $64(58 \%)$ isolates. qnrB was detected in $13(12 \%)$ isolates and qnrS in 5 (4.5\%) isolates. Two (1.8\%) isolates carried both qnrB and qurS genes. The

Keywords

- QRDR

- Plasmid

- GyrA acc $\left(6^{\prime}\right)$-lb-cr gene was found in $98(89 \%)$ isolates and oqxAB was detected in $7(6.3 \%)$ isolates. One $(0.9 \%)$ isolate carried qnrB, acc $\left(6^{\prime}\right)-\mathrm{lb}-\mathrm{cr}$ and oqxAB genes.

Conclusion The prevalence of acc (6')-Ib-cr gene is high among PMQR determinants, followed by qnrB, oqxAB and qnis.
\end{abstract}

\section{Introduction}

Klebsiella pneumoniae is a clinically important pathogen which causes a wide range of infections. ${ }^{1}$ It is the most common of the fluoroquinolone-resistant bacteria among Enterobacteriaceae. ${ }^{2}$ Ciprofloxacin is a fluoroquinolone frequently administered to treat bacterial infections. ${ }^{3}$ The emergence of fluoroquinolone resistance is rapidly rising due to its broad-spectrum of activity and consequent high-usage in the treatment of infectious disease. ${ }^{4}$

Resistance to fluoroquinolone is mediated by several mechanisms. The major mechanism is the chromosomal mutation at quinolone resistance determining regions (QRDR) encoded by DNA gyrases (gyrA and gyrB genes) and topoisomerase IV (parC and parE genes). ${ }^{5}$

The other mechanism of resistance is plasmid-mediated quinolone resistance $(\mathrm{PMQR})$ and this was first reported in 1998 in a clinical isolate of $K$. pneumoniae. ${ }^{6}$ The three PMQR mediators are the $q n r$ proteins ( $q n r A, q n r B$ and $q n r S$ ) that protect the target enzymes encoding DNA gyrase and topoisomerase IV. Yet another mechanism attributed to fluoroquinolone resistance is the $a c c\left(6^{\prime}\right)-I b$-cr gene, encoding a variant of aminoglycoside transferase which acetylates certain fluoroquinolones also. The qep $A$ and oq $x A B$ are specific 
efflux pump encoding genes that extrude fluoroquinolone from bacterial cell, thus contributing to resistance. ${ }^{7}$

$\mathrm{PMQR}$ determinants confer low-level resistance to fluoroquinolones, and they provide a favorable background for the selection of additional chromosomally encoded fluoroquinolone resistance mechanisms. ${ }^{8}$ Recently, PMQR is increasingly being reported worldwide.

The purpose of this study was to determine the presence of QRDR mutation genes and PMQR determination in clinical isolates of ciprofloxacin-resistant $K$. pneumoniae.

\section{Methods}

\section{Bacterial Isolates}

This study included 110 nonduplicate clinical isolates of ciprofloxacin-resistant K. pneumoniae obtained from hospitalized patients admitted to a tertiary healthcare hospital. The source of the clinical isolates were exudates $(n=88)$, respiratory secretions $(n=5)$, and blood $(n=17)$, and these were collected from June 2014 to May 2015. The bacterial identity was performed by automated (VITEK2 GN-card; BioMerieux, Brussels, Belgium) and conventional methods.

\section{Antimicrobial Susceptibility Testing}

The Kirby-Bauer Disk diffusion method and minimal inhibitory concentration (MIC) was performed in accordance with the Clinical Laboratory Standards Institute guidelines (CLSI 2017). ${ }^{9}$ ATCC Escherichia coli 25922 was used as a control for both disc diffusion method and MIC. The antibiotics tested by disc diffusion method were as follows: levofloxacin $(5 \mu \mathrm{g})$, ciprofloxacin ( $5 \mu \mathrm{g})$, and ofloxacin ( $5 \mu \mathrm{g}$ ) (Hi-media, Mumbai). MIC was determined by agar dilution assay for ciprofloxacin (Sigma-Aldrich, India).

\section{Preparation of Media and Antibiotic Solution}

MIC was determined using concentration derived from serial two-fold dilution indexed to the base 2 (e.g., 1, 2, 4, 8ug/ $\mathrm{mL}$ ). Two $\mathrm{mL}$ of various serial two-fold dilutions of the antimicrobial agent was added to $18 \mathrm{~mL}$ molten MHA agar. The inoculum was prepared by mixing colonies in peptone water obtained from an overnight culture of Gram negative clinical isolates grown on MacConkey Agar plate (MAC) (Himedia Laboratories, India). The agar plate with the concentration of the drug at which there were was no growth was taken as the minimum inhibitory concentration.

\section{Polymerase Chain Reaction (PCR)}

The DNA of the study isolates was extracted by the boiling method. ${ }^{10}$ The QRDR mutation genes (gyrA, gyrB, parC and parE) were detected by using specific primers, ${ }^{11}$ and the PCR conditions were as follows: $94^{\circ} \mathrm{C}$ for 3 minutes, followed by 35 cycles of denaturation at $94^{\circ} \mathrm{C}$ for 30 seconds, annealing at $55^{\circ} \mathrm{C}$ for gyrA and parE, $58^{\circ} \mathrm{C}$ for gyrB, and $52^{\circ} \mathrm{C}$ for parC for 30 seconds, with extension at $72^{\circ} \mathrm{C}$ for 50 seconds, and a final extension at $72^{\circ} \mathrm{C}$ for 10 minutes. The amplification of $q n r$ genes ( $q n r A, q n r B$ and $q n r S$ ) was performed by multiplex PCR using the cyclic profile: initial denaturation at $94^{\circ} \mathrm{C}$ for 7 minutes; denaturation at $94^{\circ} \mathrm{C}$ for 50 seconds, annealing at $53^{\circ} \mathrm{C}$ for 40 seconds, and elongation at $72^{\circ} \mathrm{C}$ for $60 \mathrm{sec}-$ onds, repeated for 35 cycles, and a final extension at $72^{\circ} \mathrm{C}$ for 5 minutes. ${ }^{12}$ PCR conditions for $a c c\left(6^{\prime}\right)-I b$-cr were: initial denaturation at $94^{\circ} \mathrm{C}$ for 7 minutes, denaturation at $94^{\circ} \mathrm{C}$ for 50 seconds, annealing at $55^{\circ} \mathrm{C}$ for 40 seconds, and elongation at $72^{\circ} \mathrm{C}$ for 60 seconds, repeated for 35 cycles, and a final extension at $72^{\circ} \mathrm{C}$ for 5 minutes. The PCR cyclic parameters for oqxAB were as follows: initial denaturation at $95^{\circ} \mathrm{C}$ for 15 minutes; 30 cycles of $94^{\circ} \mathrm{C}$ for 30 seconds, $63^{\circ} \mathrm{C}$ for $90 \mathrm{sec}-$ onds, and $72^{\circ} \mathrm{C}$ for 90 seconds; followed by a final extension at $72^{\circ} \mathrm{C}$ for 10 minutes. The PCR condition used for qepA were as follows: initial denaturation at $96^{\circ} \mathrm{C}$ for 1 minute, followed by 30 cycles of amplification at $96^{\circ} \mathrm{C}$ for 1 minute, annealing at $60^{\circ} \mathrm{C}$ for 1 minute, extension at $72^{\circ} \mathrm{C}$ for 1 minute, and the final extension step was at $72^{\circ} \mathrm{C}$ for 5 minutes. ${ }^{13,14}$ The primers used are given in - Table 1. The PCR product was examined by electrophoresis in $1.5 \%$ agarose gel containing ethidium bromide and visualized by gel documentation system.

\section{Nucleotide Sequence}

The PCR positive amplicons were sequenced by SciGenome Labs PVT. Ltd, India, and analyzed with BLAST tools (www. ncbi.nim.nih.gov).

The assigned Genbank accession numbers for the submitted sequences are as follows: MH709267 (gyrA); MH709268 (gyrB); MK318818 (parC); MK318819 (parE); MH709266 (qnrA); KY130487 (qnrB); KY130488 (qnrs); MH709269 (acc (6')-Ib-cr); MH709851 (oqxAB).

\section{Conjugation Assay}

Conjugation assay was performed to study the transfer of plasmid from qnr positive isolates which were used as donors.

Table 1 Primers used in this study

\begin{tabular}{|l|l|l|}
\hline Gene & Primers & $\begin{array}{l}\text { Product } \\
\text { size }\end{array}$ \\
\hline gyrA & $\begin{array}{l}\text { GGATAGCGGTTAGATGAGC } \\
\text { CGTTCACCAGCAGGTTAGG }\end{array}$ & 521 \\
\hline gyrB & $\begin{array}{l}\text { CAGCAGATGAACGAACTGCT } \\
\text { AACCAAGTGCGGTGATAAGC }\end{array}$ & 376 \\
\hline parC & $\begin{array}{l}\text { AATGAGCGATATGGCAGAGC } \\
\text { TTGGCAGACGGGCAGGTAG }\end{array}$ & 487 \\
\hline parE & $\begin{array}{l}\text { GCTGAACCAGAACGTTCAG } \\
\text { GCAATGTGCAGACCATCAGA }\end{array}$ & 426 \\
\hline qnrA & $\begin{array}{l}\text { 5-TCAGCAAGAGGATTTCTCA-3 } \\
\text { 5-GGCAGCACTATTA CTCCCA-3 }\end{array}$ & 516 \\
\hline qnrB & $\begin{array}{l}\text { 5-GATCGTGAAAGCCAGAAAGG3 } \\
\text { 5-ACGATG CCTGGTAGTTGTCC-3 }\end{array}$ & 469 \\
\hline qnrS & $\begin{array}{l}\text { 5-ACGACATTCGTCAACTGCAA-3 } \\
\text { 5-TAAATTGGCACCCTGTAGGC-3 }\end{array}$ & 417 \\
\hline $\begin{array}{l}\text { acc } \\
(6 ') \text {-Ib-cr }\end{array}$ & $\begin{array}{l}\text { 5-TTGGAAGCGGGGACGGAM-3 } \\
\text { 5-ACACGGCTGGACCATA -3 }\end{array}$ & 260 \\
\hline oqxAB & $\begin{array}{l}\text { 5- CCGCACCGATAAATTAGTCC-3 } \\
\text { 5-GGCGAGGTTTTGATAGTGGA-3 }\end{array}$ & 313 \\
\hline qepA & $\begin{array}{l}\text { 5-GCA GGT CCA GCA GCG GGT AG-3 } \\
\text { 5-CTT CCT GCC CGA GTA TCG TG-3 }\end{array}$ & 199 \\
\hline
\end{tabular}


Escherichia coli J53 AziR strain was used as recipient. The mating was performed in logarithmic phase by adding the donor and recipient cells $(0.5 \mathrm{~mL}$ each) in $3 \mathrm{~mL}$ of Luria-Bertani broth and incubated overnight at $37^{\circ} \mathrm{C}$. Transconjugants were selected on Macconkey agar plates containing sodium azide $(100 \mu \mathrm{g} / \mathrm{mL})$ and ciprofloxacin $(0.5 \mu \mathrm{g} / \mathrm{mL}) .^{15}$ The transconjugants were analyzed by PCR to determine the transferability of PMQR determinants.

\section{Results}

\section{Antimicrobial Susceptibility Testing}

MIC to ciprofloxacin ranged from $4 \mu \mathrm{g} / \mathrm{mL}$ to $\geq 256 \mu \mathrm{g} / \mathrm{mL}$. $\mathrm{MIC}_{50}$ and $\mathrm{MIC}_{90}$ were $32 \mu \mathrm{g} / \mathrm{mL}$ and $128 \mu \mathrm{g} / \mathrm{mL}$, respectively. All 110 isolates were resistant to ciprofloxacin, levofloxacin, and ofloxacin.

\section{Distribution of QRDR and PMQR Genes}

Among the 110 study isolates, 94 (85\%) harbored gyrA and $85(77 \%)$ gyrB. The parC and parE genes were detected in $88(80 \%)$ and $64(58 \%)$ isolates. Combination of the above four genes was found in 56 (51\%) isolates. (-Table 2). Of the eighteen (16\%) isolates which harbored the $q n r$ genes, $q n r B$ was detected in $13(12 \%)$ isolates and qnrS in 5 (4.5\%) isolates. Two (1.8\%) isolates carried both $q n r B$ and $q n r S$ genes. The acc $\left(6^{\prime}\right)-\mathrm{Ib}-\mathrm{cr}$ gene was found in $98(89 \%)$ isolates and $o q x A B$ was detected in7 (6.3\%) isolates. One (0.9\%) isolate carried $q n r B$, acc (6')-Ib-cr and oqxAB genes (- Table 3). Notably, qnrA and qepA were not detected in any of the study isolates.

\section{PMQR Gene Transfer}

Of the 18 qnr determinants, 11 (61\%) were successfully transconjugated. Among them, eight (44\%) harbored the qnrB and three (17\%) harbored qnrs gene.

Among the qnrB transconjugants, four (22\%) also carried acc $\left(6^{\prime}\right)-I b-c r$, and one coharbored the acc $\left(6^{\prime}\right)-I b-c r$ and oqxAB. qnrB alone was present in three transconjugants. Of the three qnrs transconjugants, one (5.5\%) coharbored acc (6')-Ib-cr.

Table 2 Distribution of quinolone resistance chromosomal mutation genes

\begin{tabular}{|l|l|}
\hline QRDR genes & No. of positive $(\boldsymbol{n}=110)$ \\
\hline gyrA & $94(85 \%)$ \\
\hline gyrB & $85(77 \%)$ \\
\hline parC & $88(80 \%)$ \\
\hline parE & $64(58 \%)$ \\
\hline gyrA + gyrB & $2(1.8 \%)$ \\
\hline gyrA + parE & $6(5.4 \%)$ \\
\hline gyrB + parE & $4(3.6 \%)$ \\
\hline gyrA + gyrB + parC & $28(25 \%)$ \\
\hline gyrA + parC + parE & $9(8.1 \%)$ \\
\hline gyrB + parC + parE & $2(1.8 \%)$ \\
\hline gyrA + gyrB + parC + parE & $5(4.5 \%)$ \\
\hline
\end{tabular}

Table 3 Distribution of plasmid-mediated quinolone resistance genes

\begin{tabular}{|l|l|}
\hline PMQR genes & No. of positives $(\boldsymbol{n}=110)$ \\
\hline$q n r B$ & $13(11.8 \%)$ \\
\hline$q n r S$ & $5(4.5 \%)$ \\
\hline$a c c\left(6^{\prime}\right)-I b-c r$ & $98(89 \%)$ \\
\hline oqxAB & $7(6.3 \%)$ \\
\hline$q n r B+q n r S$ & $2(1.8 \%)$ \\
\hline$q n r B+q n r S+a c c\left(6^{\prime}\right)-I b-c r+o q \times A B$ & $1(0.9 \%)$ \\
\hline
\end{tabular}

\section{Discussion}

Fluoroquinolones are the most important antibacterial agents used for the treatment of bacterial infections. ${ }^{16}$ Recently, bacterial resistance to fluoroquinolones has increased in clinical isolates. The most common resistance mechanism of fluoroquinolones are the chromosomal mutations in QRDR and PMQR ${ }^{17}$ In the present study, 110 ciprofloxacin-resistant clinical isolates of K. pneumoniae were screened to determine the prevalence of QRDR mutation genes and PMQR determinants.

In this study, a majority (88\%) of isolates exhibited highlevel of MIC to ciprofloxacin. The gyrA gene $(85 \%)$ was encountered most frequently followed by parC (80\%), gyrB (77\%), and parE (58\%). Similar high-prevalence rate for mutations in gyrA has been reported by Alisha et al from Iran and Muthu et al from India. ${ }^{18,19}$ Although the gyrA and parC are most commonly reported, mutation-resistant genes in the QRDR regions, in the current study, gyrB and parE genes were also frequently encountered.

In this study, qnrB gene (12\%) was more prevalent than $q n r S(4.5 \%)$. qnrA was not found in any isolate. Our results are consistent with the findings of previous studies. ${ }^{20-24} \mathrm{~A}$ study from Korea reported high-prevalence of qnrS (26.6\%) as compared with $q n r B(6.5 \%)$ and $q n r A$ was not detected. ${ }^{25}$ Mahesh et al and Tripathi et al from India observed $q n r A$ and $q n r B$ in clinical isolates, whereas $q n r S$ was not detected. ${ }^{26,27}$ In few studies, all the three $q n r$ genes ( $q n r A$, $q n r B$ and $q n r S$ ) have been found in clinical isolates., ${ }^{8,28,29}$ The types of $q n r$ genes may vary in different geographical locations. ${ }^{30}$ Conjugation experiment demonstrated that $61 \%$ of $q n r$ determinants are transferable, where one transconjugant carrying multiple PMQR genes was documented. This transferability rate is high compared with previous studies. ${ }^{31-33}$

In the present study, the prevalence of oqxAB gene (6.3\%) was very low as compared with previous reports. . $^{23,29,31}$ Thus, indicating that it may not be a major mediator of fluoroquinolone resistance. qepA gene was not detected in the present study and similar findings has been documented from Thailand and Iran. ${ }^{34,35}$ In contrast, qepA gene was detectable in a study conducted by Majida et al, and in the same study, oqxAB was notably absent. ${ }^{30}$ However, from India, only a few studies have reported oqxAB and qepA genes in Enterobacteriaceae. 
In this study, $a c c\left(6^{\prime}\right)$-Ib-cr was predominantly present along with $\mathrm{PMQR}$ genes. Similar to this result, a high-prevalence was noted in Iran, Korea and Israel. ${ }^{22,35,36}$ In agreement to the previous reports, all the $q n r$ determinants were positive for acc (6')-Ib-cr gene. ${ }^{37-40} \mathrm{~A}$ high-frequency of the combined occurrence of acc (6')-Ib-cr and QRDR mutations and PMQR determinants in multidrug resistant $K$. pneumoniae has been reported from Brazil. ${ }^{8}$ Limited data have been reported on the prevalence of fluoroquinolone resistance in India. These results suggest that the emergence of the PMQR would contribute to a rapid increase and spread in bacterial resistance to fluoroquinolones, which requires continuous surveillance and monitoring of antibiotic use. The limitation of this study is the lack of analysis of efflux pump activity.

\section{Conclusion}

The current study demonstrated a high prevalence of aac (6')$I b$-cr gene among PMQR determinants. The transferability rate of these determinants is high. This is a cause for concern, since horizontal transfer of PMQR genes can increase the spread of fluoroquinolone resistance among clinical isolates.

\section{Funding}

This study was funded by Department of Science and Technology (DST) under Women Scientists Scheme (WOS-A).

\section{Conflict of Interest}

None.

\section{References}

1 Poirel L, Cattoir V, Nordmann P. Plasmid mediated quinolone resistance; interactions between human, animal and environmental ecologies. Front Microbiol 2012;3:24-27

2 Hooper DC, Jacoby GA. Mechanisms of drug resistance: quinolone resistance. Ann N Y Acad Sci 2015;1354(1):12-31

3 Briales A, Rodríguez-Martínez JM, Velasco C, et al. Prevalence of plasmid-mediated quinolone resistance determinants qnr and aac(6')-Ib-cr in Escherichia coli and Klebsiella pneumoniae producing extended-spectrum $\beta$-lactamases in Spain. Int J Antimicrob Agents 2012;39(5):431-434

4 Shams E, Firoozeh F, Moniri R, Zibaei M. Prevalence of plasmid-mediated quinolone resistance genes among extended-spectrum $\beta$-Lactamase-producing Klebsiella pneumoniae human isolates in Iran. J Pathogens 2015;2015:434391

5 Strahilevitz J, Jacoby GA, Hooper DC, Robicsek A. Plasmidmediated quinolone resistance: a multifaceted threat. Clin Microbiol Rev 2009;22(4):664-689

6 Redgrave LS, Sutton SB, Webber MA, Piddock LJ. Fluoroquinolone resistance: mechanisms, impact on bacteria, and role in evolutionary success. Trends Microbiol 2014;22(8):438-445

7 Machuca J, Briales A, Labrador G, et al. Interplay between plasmid-mediated and chromosomal-mediated fluoroquinolone resistance and bacterial fitness in Escherichia coli. J Antimicrob Chemother 2014;69(12):3203-3215

8 Araújo BF, Campos PA, Royer S, et al. High frequency of the combined presence of QRDR mutations and PMQR determinants in multidrug-resistant Klebsiella pneumoniae and Escherichia coli isolates from nosocomial and community-acquired infections. J Med Microbiol 2017;66(8):1144-1150

9 Clinical and Laboratory Standards Institute, Performance Standards for Antimicrobial Susceptibility Testing. M100, 27th ed. Wanye (PA): Clinical and Laboratory Standards Institute; 2017

10 Pérez-Pérez FJ, Hanson ND. Detection of plasmid-mediated AmpC beta-lactamase genes in clinical isolates by using multiplex PCR. J Clin Microbiol 2002;40(6):2153-2162

11 Tarchouna M, Ferjani A, Marzouk M, et al. Prevalence of plasmid-mediated quinolone resistance determinants among clinical isolates of Escherichia coli in a Tunisian hospital. Int J Curr Microbiol Appl Sci 2015;4(3):195-206

12 Robicsek A, Strahilevitz J, Sahm DF, Jacoby GA, Hooper DC. qnr prevalence in ceftazidime-resistant Enterobacteriaceae isolates from the United States. Antimicrob Agents Chemother 2006;50(8):2872-2874

13 Wareham DW, Umoren I, Khanna P, Gordon NC. Allele-specific polymerase chain reaction (PCR) for rapid detection of the aac $\left(6^{\prime}\right)$-lb-cr quinolone resistance gene. Int J Antimicrob Agents 2010;36(5):476-477

14 Saleh MA, Balboula MM. Plasmid mediated quinolone resistance determinants among nosocomial clinical Pseudomonas aeruginosa isolates. Int J Curr Microbiol Appl Sci 2017;6(1):42-50

15 Wang M, Tran JH, Jacoby GA, Zhang Y, Wang F, Hooper DC. Plasmid-mediated quinolone resistance in clinical isolates of Escherichia coli from Shanghai, China. Antimicrob Agents Chemother 2003;47(7):2242-2248

16 Cattoir V, Nordmann P. Plasmid-mediated quinolone resistance in gram-negative bacterial species: an update. Curr Med Chem 2009;16(8):1028-1046

17 Correia S, Poeta P, Hébraud M, Capelo JL, Igrejas G. Mechanisms of quinolone action and resistance: where do we stand? J Med Microbiol 2017;66(5):551-559

18 Akya A, Lorestani RC, Elahi A, et al. The impact of mutations in topoisomerase genes and the plasmid-mediated quinolone resistance (PMQR) determinants on the resistance to fluoroquinolones in Klebsiella pneumoniae. Arch Clin Infect Dis 2017;14(4):57290

19 Muthu G, Mangaiyarkarasi T, Vishnuprabu, Sathiskumar E, Srivani S. Detection of gyrA ser83 mutation and parCgene amplification in E.coli and Klebsiella pneumoniae from tertiary care hospital, Puducherry. Int J Med Microbiol Tropical Dis 2017;3(4):167-170

20 Minarini LAR, Poirel L, Cattoir V, Darini AL, Nordmann P. Plasmid-mediated quinolone resistance determinants among enterobacterial isolates from outpatients in Brazil. J Antimicrob Chemother 2008;62(3):474-478

21 Kim HB, Park CH, Kim CJ, Kim EC, Jacoby GA, Hooper DC. Prevalence of plasmid-mediated quinolone resistance determinants over a 9-year period. Antimicrob Agents Chemother 2009;53(2):639-645

22 Yang HY, Nam YS, Lee HJ. Prevalence of plasmid-mediated quinolone resistance genes among ciprofloxacin-nonsusceptible Escherichia coli and Klebsiella pneumoniae isolated from blood cultures in Korea. Can J Infect Dis Med Microbiol 2014;25(3):163-169

23 El-Badawy MF, Tawakol WM, El-Far SW, et al. Molecular identification of aminoglycoside-modifying enzymes and plasmid-mediated quinolone resistance genes among Klebsiella pneumoniae clinical isolates recovered from Egyptian patients. Int J Microbiol 2017;2017:8050432

24 Majlesi A, Kakhki RK, Mozaffari Nejad AS, et al. Detection of plasmid-mediated quinolone resistance in clinical isolates of 
Enterobacteriaceae strains in Hamadan, West of Iran. Saudi J Biol Sci 2018;25(3):426-430

25 Hamed SM, Elkhatib WF, El-Mahallawy HA, Helmy MM, Ashour MS, Aboshanab KMA. Multiple mechanisms contributing to ciprofloxacin resistance among Gram negative bacteria causing infections to cancer patients. Sci Rep 2018;8(1):12268

26 Magesh H, Kamatchi C, Vaidyanathan R, Sumathi G. Identification of plasmid-mediated quinolone resistance genes qnrA1, qnrB1 and aac(6')-1b-cr in a multiple drug-resistant isolate of Klebsiella pneumoniae from Chennai. Indian J Med Microbiol 2011;29(3):262-268

27 Tripathi A, Dutta SK, Majumdar M, Dhara L, Banerjee D, Roy K. High prevalence and significant association of ESBL and QNR genes in pathogenic Klebsiella pneumoniae isolates of patients from Kolkata, India. Indian J Microbiol 2012;52(4):557-564

28 Vali L, Dashti AA, Jadaon MM, El-Shazly S. The emergence of plasmid mediated quinolone resistance qnrA2 in extended spectrum $\beta$-lactamase producing Klebsiella pneumoniae in the Middle East. Daru 2015;23(1):34

29 Goudarzi M, Azad M, Seyedjavadi SS. Prevalence of plasmid-mediated quinolone resistance determinants and OqxAB efflux pumps among extended-spectrum $\beta$-lactamase producing Klebsiella pneumoniae isolated from patients with nosocomial urinary tract infection in Tehran, Iran. Scientifica (Cairo) 2015;2015:518167

30 Alshammari MM, Ali Al-Skhattat H. . Detection of plasmid-mediated quinolone resistance genes in clinical and environmental hospital isolates of Klebsiella pneumoniae in Al-Najaf City. Kufa Journal For Nursing Sciences 2015;5(2):1-9

31 Rodríguez-Martínez JM, Díaz de Alba P, Briales A, et al. Contribution of OqxAB efflux pumps to quinolone resistance in extended-spectrum- $\beta$-lactamase-producing Klebsiella pneumoniae. J Antimicrob Chemother 2013;68(1):68-73

32 Wang A, Yang Y, Lu Q et al. Presence of qnr gene in Escherichia coli and Klebsiella pneumoniae resistant to ciprofloxacin isolated from pediatric patients in China. BMC Infect Dis 2008;8:68
33 Cai X, Li C, Huang J, et al. Prevalence of plasmid- mediated quinolone resistance qnr gene in Central China. Afr J Microbiol Res 2011;5:975-978

34 Pasom W, Chanawong A, Lulitanond A, Wilailuckana C, Kenprom S, Puang-Ngern P. Plasmid-mediated quinolone resistance genes, aac( $\left.6^{\prime}\right)-\mathrm{Ib}-\mathrm{cr}$, qnrS, qnrB, and qnrA, in urinary isolates of Escherichia coli and Klebsiella pneumoniae at a teaching hospital, Thailand. Jpn J Infect Dis 2013;66(5):428-432

35 Eftekhar F, Seyedpour SM. Prevalence of qnr and aac( $\left(6^{\prime}\right)-\mathrm{Ib}-\mathrm{cr}$ Genes in Clinical Isolates of Klebsiella Pneumoniae from Imam Hussein Hospital in Tehran. Iran J Med Sci 2015;40(6):515-521

36 Chmelnitsky I, Hermesh O, Navon-Venezia S, Strahilevitz J, Carmeli Y. Detection of aac( $\left.6^{\prime}\right)-\mathrm{Ib}-\mathrm{cr}$ in KPC-producing Klebsiella pneumoniae isolates from Tel Aviv, Israel. J Antimicrob Chemother 2009;64(4):718-722

37 Karah N, Poirel L, Bengtsson S, et al; Norwegian Study Group on PMQR. Plasmid-mediated quinolone resistance determinants qnr and aac $\left(6^{\prime}\right)-\mathrm{Ib}-\mathrm{cr}$ in Escherichia coli and Klebsiella spp. from Norway and Sweden. Diagn Microbiol Infect Dis 2010;66(4):425-431

38 Deepak RN, Koh TH, Chan KS. Plasmid-mediated quinolone resistance determinants in urinary isolates of Escherichia coli and Klebsiella pneumoniae in a large Singapore hospital. Ann Acad Med Singapore 2009;38(12):1070-1073

39 Ode T, Saito R, Kumita W, et al. Analysis of plasmid-mediated multidrug resistance in Escherichia coli and Klebsiella oxytoca isolates from clinical specimens in Japan. Int J Antimicrob Agents 2009;34(4):347-350

40 Shin SY, Kwon KC, Park JW, et al. Characteristics of aac(6')Ib-cr gene in extended-spectrum beta-lactamase-producing Escherichia coli and Klebsiella pneumoniae isolated from Chungnam area. Korean J Lab Med 2009;29(6):541-550 